\title{
Fotossensibilidade como Manifestação Inicial de Infeção por Vírus da Imunodeficiência Humana
}

\author{
Maria Relvas', Francisca Morgado', Hugo Oliveira', Margarida Gonçalo ${ }^{1,2}$ \\ 'Departamento de Dermatologia, Centro Hospitalar e Universitário de Coimbra. Coimbra, Portugal \\ ${ }^{2}$ Departamento de Dermatologia, Faculdade de Medicina. Universidade de Coimbra. Coimbra, Portugal
}

RESUMO - As reações de fotossensibilidade caracterizam-se por uma resposta alterada à radiação não-ionizante, apresentando diversos padrões morfológicos, que refletem as suas diferentes etiologias. Relatamos o caso de um doente observado por dermatose fotossensível refratária a múltiplos tratamentos. Excluídas possíveis causas exógenas e após demonstração de uma dose de eritema mínimo diminuída para UVB, o estudo analítico com vista a iniciar azatioprina revelou serologia positiva para VIH, revelando elevada carga viral e contagens TCD4+ reduzidas. Neste seguimento, iniciou de imediato terapêutica anti-retroviral, com resolução rápida e completa do quadro. Estima-se que $5 \%$ dos doentes VIH-positivos apresentem fotossensibilidade em algum momento da sua evolução. Mais frequentemente associada a fármacos utilizados no tratamento, a sensibilidade à luz solar tem também sido ocasionalmente descrita como manifestação inicial da infeção, como no presente caso. Os autores pretendem alertar para a associação entre fotossensibilidade e infeção por VIH que, embora tenha vindo a ser crescentemente reconhecida, está ainda pouco caracterizada.

PALAVRAS-CHAVE - Fotossensibilidade; Infecções por VIH7complicações.

\section{Photosensitivity as the Presenting Feature of Human Immunodeficiency Virus Infection}

\begin{abstract}
Photosensitivity is characterized by an abnormal response to non-ionizing radiation, disclosing a variety of morphological patterns, which reflect their different etiologies. We describe the case of a man presenting with a photosensitive dermatosis with no apparent exogenous cause and refractory to multiple treatments. Phototests revealed a reduction in minimal erythema dose to UVB. Laboratory tests in order to start azathioprine, showed a positive test for HIV and a diagnosis of AIDS (high viral load and low TCD4+ cells). A few months after starting antiretroviral therapy photosensitivity resolved completely. Photosensitivity affects up to $5 \%$ of HIV-positive patients, mostly due to drug photosensitivity, but it has also been reported as the presenting sign. The authors emphasize the clinical association between HIV infection and photosensitivity which has been increasingly recognized, although it is still poorly characterized from a clinical and photobiological point of view.
\end{abstract}

KEYWORDS - HIV Infections/complications; Photosensitivity Disorders.

\section{INTRODUÇÃO}

As reações de fotossensibilidade caracterizam-se por uma resposta cutânea alterada à radiação não-ionizante, traduzindo-se numa variedade de padrões clínicos que refletem as suas diversas causas.' Estas podem resultar de uma resposta tecidular anómala à absorção da radiação por moléculas endógenas ou ser causadas por compostos foto-ativos, quer de origem endógena, como as porfirinas, quer exógena, como fármacos ou químicos administrados sistemicamente ou aplicados diretamente na pele. ${ }^{2}$

O reconhecimento de um padrão de fotossensibilidade pressupõe o atingimento de áreas foto-expostas como a face, pavilhões auriculares, região cervical posterior, " $\mathrm{V}$ " do decote e dorso das mãos, poupando as áreas sombra, como a região retro-auricular, pregas nasogenianas, pálpebras superiores e zona submentoniana. ${ }^{3}$
Correspondência: Maria Relvas

Departamento de Dermatologia

Centro Hospitalar e Universitário de Coimbra

Praceta Prof. Mota Pinto

3004-561 Coimbra, Portugal

E-mail: mariavrelvas@gmail.com

DOI: https://dx.doi.org/10.29021/spdv.78.3.1208
Recebido/Received 2019/05/06

(C) Autor (es) (ou seu (s) empregador (es)) 2020 Revista SPDV. Reutilização permitida de acordo com CC BY-NC. Nenhuma reutilização comercial.

(c) Author(s) (or their employer(s)) 2020 SPDV Journal. Re-use permitted under CC BY-NC. No commercial re-use. 


\section{Caso Clínico}

\section{CASO CLÍNICO}

Doente de 58 anos, género masculino, fototipo III, operário na construção de estradas, observado por dermatose pruriginosa da face, com 2 meses de evolução. Sem história de alergias medicamentosas ou introdução recente de novos fármacos e sem qualquer queixa sistémica. Previamente medicado com aceponato de metilprednisolona $0,1 \%$ creme e bilastina $20 \mathrm{mg}$ em SOS, sem qualquer benefício.

Ao exame dermatológico verificava-se eritema vermelho vivo levemente descamativo, bem demarcado, da face e do pescoço, poupando as regiões palpebrais, sulcos nasogenianos e área inframentoniana, sendo compatível com padrão de fotossensibilidade (Fig. 1). Não apresentava outras anomalias ao exame físico, nomeadamente adenopatias cervicais.

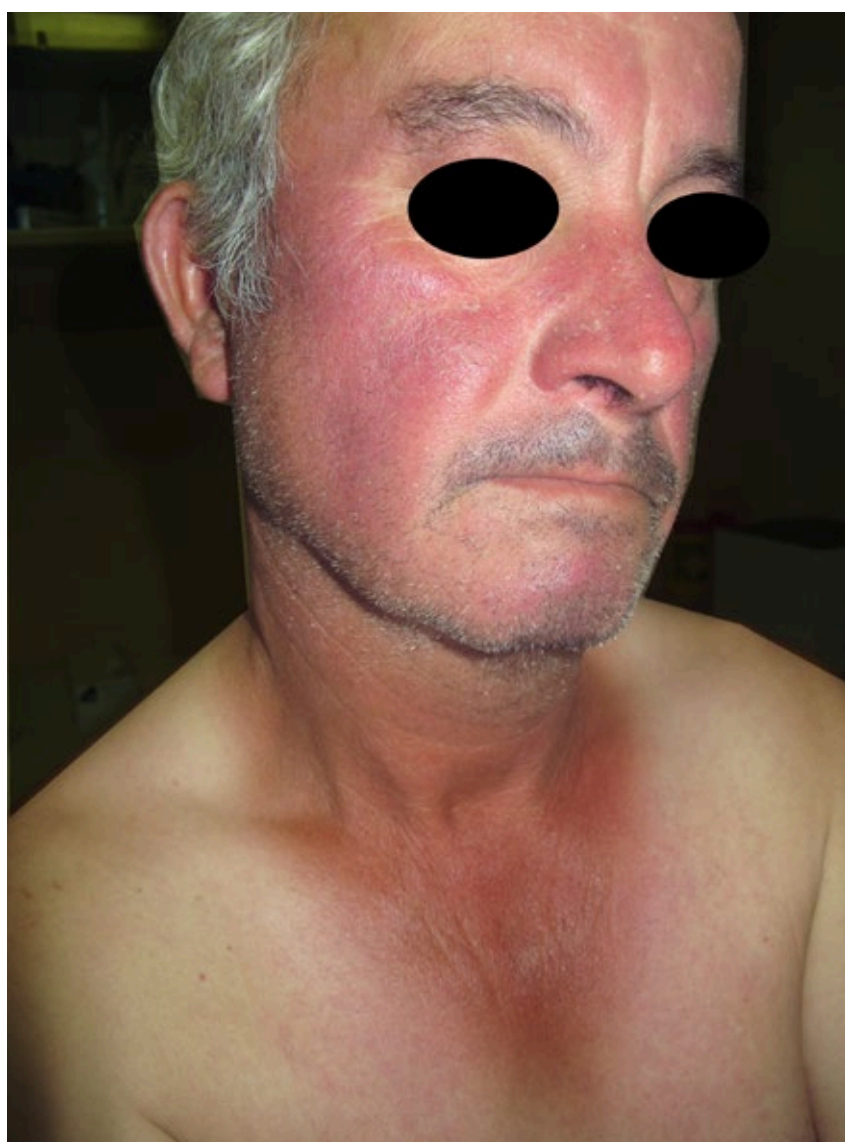

Figura 1 - Eritema levemente descamativo, bem demarcado, da face e do pescoço, poupando as regiões palpebrais, sulcos nasogenianos e área inframentoniana, compatível com padrão de fotossensibilidade.

Realizou testes epicutâneos, que incluíram a série básica do Grupo Português de Estudo das Dermatites de Contacto e as séries de plantas e cosméticos/veículos de tópicos, bem como testes foto-epicutâneos, com a série de foto-alergénios Europeia (Chemotechnique Diagnostics, Vellinge, Suécia)

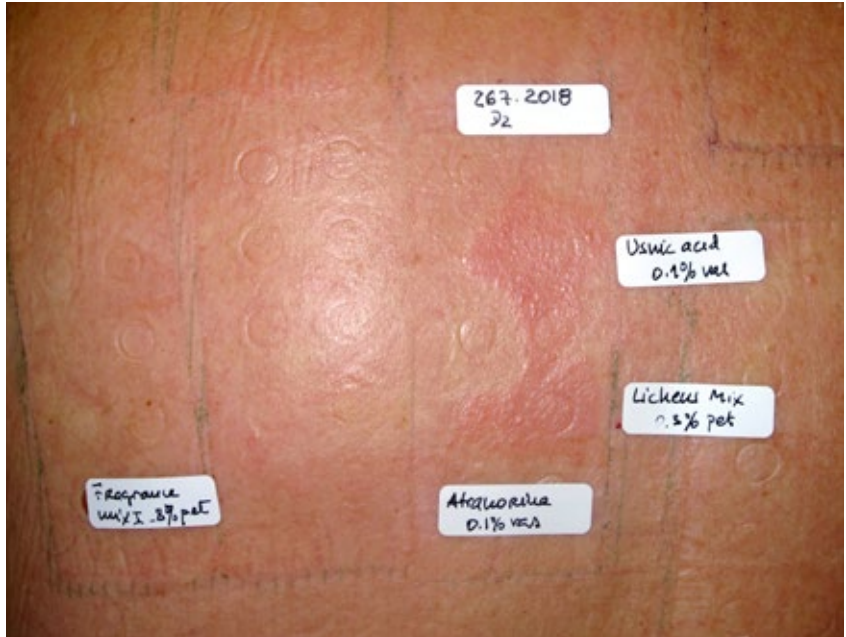

Figura 2 - Resultados dos testes epicutâneos: reação positiva fraca $(1+)$ a componentes de líquens (mistura de ácidos liquénicos 0,3\% vas, ácido único $0,1 \%$ vas e atranorina $0,1 \%$ vas).

irradiados com $5 \mathrm{~J} / \mathrm{cm}^{2}$ de UVA (Waldmann ${ }^{\circledR} 7001 \mathrm{~K}$ ). Observou-se uma reação positiva fraca $(1+)$ apenas a componentes de líquens (mistura de ácidos liquénicos $0,3 \%$ vas, ácido único $0,1 \%$ vas e atranorina $0,1 \%$ vas), sem foto-agravamento (Fig. 2).

Dada a dificuldade em evitar a exposição aos líquens perante a sua profissão, cumpriu um ciclo de corticoterapia oral (24 mg/dia de metilprednisolona em esquema de desmame durante 15 dias), e tópica (aceponato de metilprednisolona $0,1 \%$ creme durante 10 dias), que se mostraram pouco úteis, com manutenção do quadro 3 meses após a primeira visita.

Foram posteriormente realizados fototestes, em áreas de $5 \times 5 \mathrm{~cm}$ de pele sã, não exposta do dorso, a doses crescentes de UVA e UVB, utilizando como fonte de irradiação a câmara Waldmann ${ }^{\circledR} 7001 \mathrm{~K}$. Estes demonstraram ausência de reação cutânea às 24 e 48 horas após irradiação com 5, 10 e 15 J/ $\mathrm{cm}^{2}$ de UVA, mas eritema para doses iguais ou superiores a $0,5 \mathrm{~J} / \mathrm{cm}^{2}$ de UVB $311 \mathrm{~nm}$, implicando uma discreta redução da dose de eritema mínimo para o seu fototipo (Fig. 3).

Atendendo ao quadro clínico, que evocava a possibilidade de dermatite actínica crónica, ponderou-se iniciar azatioprina, procedendo-se à colheita de estudo analítico, incluindo hemograma, marcadores de função hepática, renal e serologias infeciosas. Os parâmetros encontravam-se normais, à exceção de uma positividade para o vírus da imunodeficiência humana (VIH)-1, confirmado por ELISA de quarta geração. $O$ estudo subsequente revelou uma carga viral de 91 700 cópias/mL e uma contagem de células T CD4+ de 147 células $/ \mathrm{mm}^{3}$, consubstanciando o diagnóstico de síndrome da imunodeficiência adquirida.

Neste seguimento, iniciou terapêutica anti-retroviral com tenofovir/emtricitabina e dolutegavir, verificando-se resolução rápida e completa do prurido e das lesões fotossensíveis (Fig. 4). O doente mantém terapêutica anti-retroviral e fotoproteção sem recorrência da sintomatologia após 1 ano de seguimento, apesar da mesma exposição profissional. 


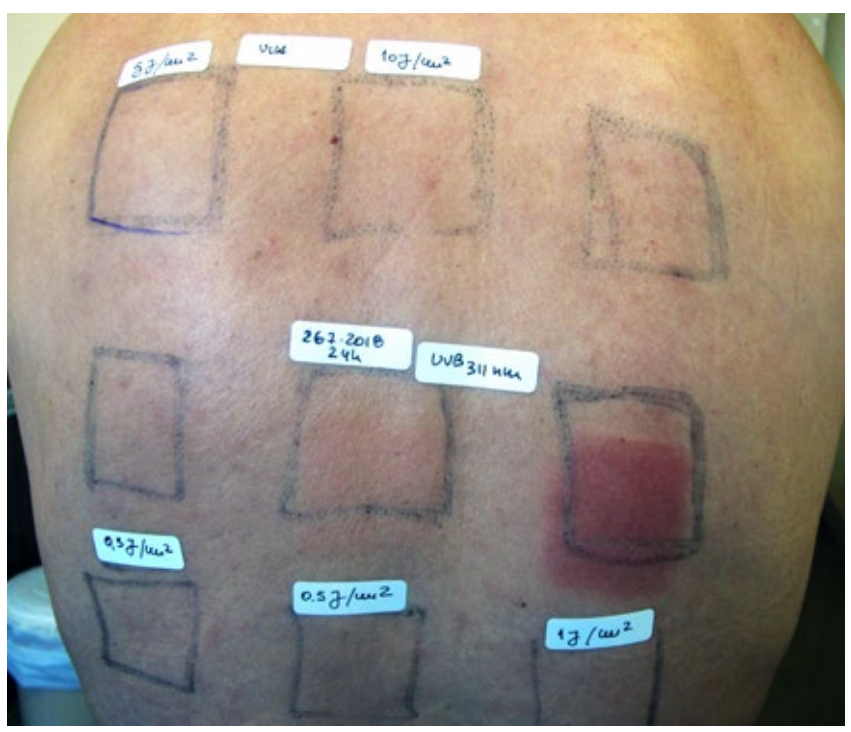

Figura 3 - Resultados dos fototestes: ausência de reação para 5, 10 e $15 \mathrm{~J} / \mathrm{cm}^{2}$ de UVA; discreto eritema para $0,5 \mathrm{~J} / \mathrm{cm}^{2}$ e eritema franco para $1 \mathrm{~J} / \mathrm{cm}^{2}$ de UVB $311 \mathrm{~nm}$.

\section{DISCUSSÃO}

Estima-se que em algum momento da sua evolução $5 \%$ dos doentes com infecção por VIH apresentem fotossensibilidade. ${ }^{3}$ Habitualmente associada a fármacos utilizados no seu tratamento, tem também sido descrita sob a forma de dermatoses fotossensíveis ou, mais raramente, como manifestação inicial da infeção pelo vírus. ${ }^{4}$
Os fármacos mais frequentemente implicados compreendem os agentes anti-retrovirais, destacando-se o efavirenz e o saquinavir, trimetoprim-sulfametoxazol, anti-inflamatórios não esteroides, cetoconazol, azitromicina e dapsona. ${ }^{4-6}$ Neste contexto, apresentam-se como reações fototóxicas, fotoalérgicas ou erupções liquenóides fotossensíveis, sendo as últimas principalmente observadas com administração de trimetoprim-sulfametoxazol e anti-inflamatórios não esteroides. ${ }^{3}$

A fotossensibilidade em doentes com infecção $\mathrm{VIH}$ pode também ocorrer sob a forma de outras dermatoses fotossensíveis como a porfiria e pseudo-porfiria cutânea tarda, granuloma anular fotossensível, hiperpigmentação facial primária, despigmentação tipo-vitiligo, pelagra, eritrodermia e dermatite actínica crónica. ${ }^{3,6-8}$

Embora menos descrita, a fotossensibilidade pode ainda constituir a manifestação inicial (e única) da infeção por VIH. 4,6 Também nesta situação, foram identificados diversos quadros morfológicos, alguns mais específicos que outros, em que o mais recorrentemente observado demonstra características semelhantes às de dermatite actínica crónica. 1,9,10

Sabe-se que um dos efeitos da radiação ultravioleta diz respeito à produção de espécies reativas de oxigénio resultando em dano de $A D N$ e destruição celular. Já os mecanismos subjacentes ao maior risco de desenvolvimento de fotossensibilidade em doentes com VIH não estão totalmente estabelecidos. Uma das teorias propostas consiste na disfunção das vias de neutralização de radicais livres originando maior produção de espécies reativas de oxigénio. ${ }^{3,6}$ Esta disfunção pode dever-se a uma deficiência relativa de glutationa e tioredoxina, a alterações na absorção de vitaminas e flavonoides
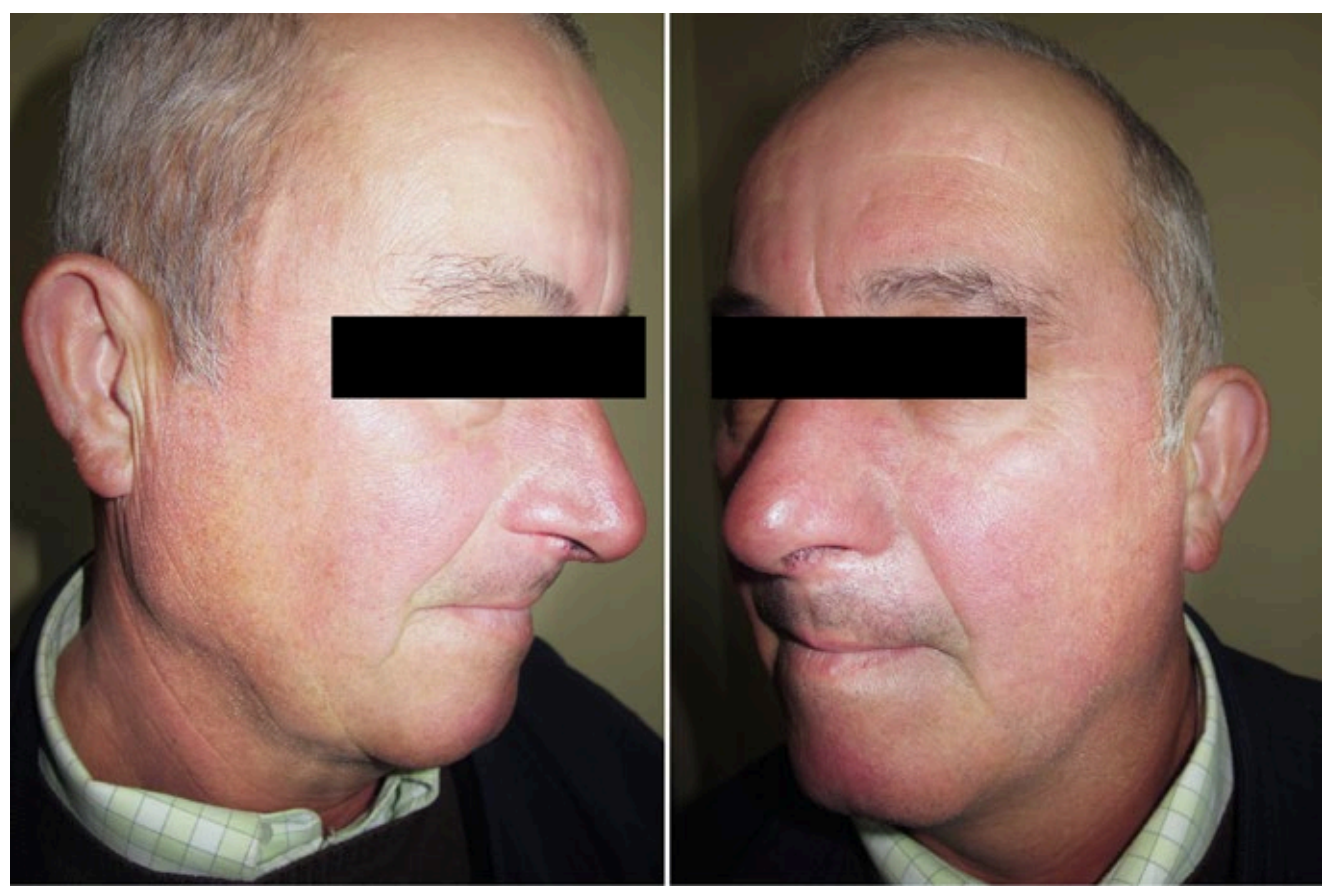

Figura 4 - Resolução completa do quadro de fotossensibilidade 6 meses após início de terapêutica anti-retroviral. 


\section{Caso Clínico}

ou a dano hepático secundário à administração de fárma$\cos ^{12}$

Verifica-se também uma relação entre o grau de imunossupressão e a ocorrência de fotossensibilidade, sendo mais frequentemente reportada em doentes com contagens de células T CD4+ inferiores a 200 células $/ \mathrm{mm}^{3}, 3,6,9-11$ tal como acontece no caso reportado. Nestas situações, o padrão mais descrito corresponde a um quadro eczematoso crónico. ${ }^{6}$

A abordagem perante um quadro eczematoso com fotossensibilidade passa, inicialmente, pela exclusão de causas farmacológicas ou outros agentes exógenos, com auxílio a testes foto-epicutâneos. ${ }^{3}$ Esta deverá posteriormente ser orientada segundo as manifestações clínicas com eventual recurso a estudo analítico (incluindo serologias de hepatites, doseamento de porfirinas séricas/urinárias, ferro, vitaminas e anticorpos anti-nucleares), fototestes e biópsia cutânea. ${ }^{3} \mathrm{~A}$ instituição terapêutica mais direcionada dependerá da etiologia do quadro, sendo a fotoproteção e evicção solar essenciais em todas as condições. ${ }^{3,9}$

Em situações de fotossensibilidade sem causa aparente, pretendemos relembrar a associação à infeção $\mathrm{VIH}$, de modo a estabelecer-se um diagnóstico correto e um tratamento adequado.

Apesar da fotossensibilidade em doentes com $\mathrm{VIH}$ ter vindo a ser crescentemente reconhecida como uma entidade clínica distinta, permanece ainda um desafio diagnóstico, devido não só à heterogeneidade de manifestações clínicas, mas também à escassa caracterização do ponto de vista fotobiológico e fisiopatológico.

Conflitos de interesse: Os autores declaram a inexistência de conflitos de interesse na realização do presente trabalho.

Fontes de financiamento: Não existiram fontes externas de financiamento para a realização deste artigo.

Confidencialidade dos dados: Os autores declaram ter seguido os protocolos da sua instituição acerca da publicação dos dados de doentes.

Consentimento: Consentimento do doente para publicação obtido.

Proveniência e revisão por pares: Não comissionado; revisão externa por pares.

Conflicts of interest: The authors have no conflicts of interest to declare.

Financing support: This work has not received any contribution, grant or scholarship.

Confidentiality of data: The authors declare that they have followed the protocols of their work center on the publication of data from patients.

Patient Consent: Consent for publication was obtained.

Provenance and peer review: Not commissioned; externally peer reviewed
ORCID

Francisca Jácome Morgado

http://orcid.org/0000-0001-5006-4334

Margarida Gonçalo

http://orcid.org/0000-0001-6842-1360

\section{REFERÊNCIAS}

1. Pappert A, Grossman M, DeLeo V. Photosensitivity as the presenting illness in four patients with human immunodeficiency viral infection. Arch Dermatol. 1994;130:618-23.

2. Lim HW, Hawk JLM, Rosen CF. Photodermatologic Disorders. In: Bolognia JL, Schaffer JV, Cerroni L, editors. Dermatology. 4th ed. Philadelphia: Elsevier Saunders; 2018. p. 1548-68.

3. Koch K. Photosensitive disorders in HIV. South Afr J HIV Med. 2017;18:676.

4. Lopez-Lerma I, Alsina MM, Blanco JL, Lecha M. Photodermatitis in a patient with HIV infection. J Am Acad Dermatol. 2003;49:159-60. doi: 10.1016/s01909622(03)70102-9.

5. Winter AJ, Pywell JM, Ilchyshyn JM, Fearn J, Natin D. Photosensitivity due to saquinavir. Genitourin Med. 1997;73:323.

6. Bilu D, Mamelak AJ, Nguyen RH, Queiroz PC, Kowalski J, Morison WL, et al. Clinical and epidemiologic characterization of photosensitivity in HIV-positive individuals. Photodermatol Photoimmunol Photomed. 2004 ;20: 175 83. doi: 10.1111/i.1600-0781.2004.00101.x.

7. Gregory N, DeLeo VA. Clinical manifestations of photosensitivity in patients with human immunodeficiency virus infection. Arch Dermatol. 1994;130:630-3.

8. Philips RC, Motaparthi K, Krishnan B, Hsu S. HIV photodermatitis presenting with widespread vitiligo-like depigmentation. Dermatol Online J. 2012;18:6.

9. Vin-Christian K, Epstein JH, Maurer TA, McCalmont TH, Berger TG. Photosensitivity in HIV-infected individuals. J Dermatol. 2000;27:361-9.

10. Wong SN, Khoo LS. Chronic actinic dermatitis as the presenting feature of HIV infection in three Chinese males. Clin Exp Dermatol. 2003;28:265-8. doi: 10.1046/i.1365-2230.2003.01249.x.

11. Meola T, Sanchez M, Lim HW, Buchness MR, Soter NA. Chronic actinic dermatitis associated with human immunodeficiency virus infection. $\mathrm{Br} J$ Dermatol. 1997; 137:431-6.

12. Cockerell JC, Calame A. Cutaneous manifestations of HIV disease. London: Manson Publishing; 2012. 